\title{
Gambling in contests with heterogeneous loss constraints
}

Citation for published version (APA):

Seel, C. (2015). Gambling in contests with heterogeneous loss constraints. Economics Letters, 136, 154157. https://doi.org/10.1016/j.econlet.2015.09.002

Document status and date:

Published: 01/11/2015

DOI:

10.1016/j.econlet.2015.09.002

Document Version:

Publisher's PDF, also known as Version of record

Document license:

Taverne

Please check the document version of this publication:

- A submitted manuscript is the version of the article upon submission and before peer-review. There can be important differences between the submitted version and the official published version of record.

People interested in the research are advised to contact the author for the final version of the publication, or visit the DOI to the publisher's website.

- The final author version and the galley proof are versions of the publication after peer review.

- The final published version features the final layout of the paper including the volume, issue and page numbers.

Link to publication

\footnotetext{
General rights rights.

- You may freely distribute the URL identifying the publication in the public portal. please follow below link for the End User Agreement:

www.umlib.nl/taverne-license

Take down policy

If you believe that this document breaches copyright please contact us at:

repository@maastrichtuniversity.nl

providing details and we will investigate your claim.
}

Copyright and moral rights for the publications made accessible in the public portal are retained by the authors and/or other copyright owners and it is a condition of accessing publications that users recognise and abide by the legal requirements associated with these

- Users may download and print one copy of any publication from the public portal for the purpose of private study or research.

- You may not further distribute the material or use it for any profit-making activity or commercial gain

If the publication is distributed under the terms of Article $25 \mathrm{fa}$ of the Dutch Copyright Act, indicated by the "Taverne" license above, 


\title{
Gambling in contests with heterogeneous loss constraints
}

\author{
Christian Seel ${ }^{*}$ \\ Department of Economics (AE1), Maastricht University, PO Box 616, 6200 MD Maastricht, The Netherlands
}

\section{H I G H L I G H T S}

- I study an asymmetric stochastic contest model.

- Players differ in their ability to make debt.

- The unique equilibrium outcome and payoffs are characterized in closed form.

- A higher debt level of a player changes the bankruptcy risk of both players.

- The similarity of the equilibrium to other contest models is explored.

\section{A R T I C L E I N F O}

\section{Article history}

Received 17 July 2015

Received in revised form

26 August 2015

Accepted 4 September 2015

Available online 1 October 2015

\section{JEL classification}

C72

$\mathrm{C} 73$

D81

Keywords:

Contest

Risk-taking

Credit line

\begin{abstract}
A B S T R A C T
I study the impact of asymmetric loss constraints on risk-taking behavior in the contest model of Seel and Strack (2013). I derive the unique Nash equilibrium outcome, the equilibrium payoffs and comparative statics about the bankruptcy risk.
\end{abstract}

(c) 2015 Elsevier B.V. All rights reserved.

\section{Introduction}

A contest is a simple and widely used mechanism in which each player's payoff is determined by his rank in a peer group. The main focus of the literature on contests has been on the trade-off between a higher effort cost and a higher chance of winning; see, e.g., Hillman and Samet (1987), Baye et al. (1996), or Siegel (2009, 2010). Applications of such contests include patent races, political campaigns, litigation, rent seeking, procurement and so forth.

In many contests in the financial industry, however, risk-taking is an important determinant of contest success. For example, think about competitions between private equity funds or mutual funds in which only the best performing funds receive substantial capital inflow in the next period or bonus payments for fund managers or CEO's if they outperform their peers. In order to focus on the risktaking aspect, Seel and Strack (2013) proposed a contest model

\footnotetext{
* Tel.: +31 433883651; fax: +31 433882000 .

E-mail address: c.seel@maastrichtuniversity.nl.
}

in which each player decides when to stop a privately observed Brownian motion and the player who stops his process at the highest value receives a prize. Thus, waiting longer entails the risk that the value of the process decreases.

During the last years, different versions of the model have been considered in the finance literature. For instance, Feng and Hobson (2015, in press-a,b) study the effects of regret-based agents, bidding caps, a random initial value, and different stochastic processes on the equilibrium outcome. In another interesting contribution, Fang and Noe (2015) establish an equivalence result between the stochastic contest model and a static model in which players choose a cumulative distribution function subject to a capacity constraint on the expected value. Moreover, they introduce multiple prizes and incomplete information and they analyze the probability of selecting more able contestants with this contest.

This paper contributes to the recent literature by focusing on another factor which influences risk-taking and which occurs in many applications in finance: contestants differ in their credit line, i.e., the maximal amount of money which they can lose. This introduces additional technical difficulties, since there are 
no simple boundary conditions as in Seel and Strack (2013); the equivalent model of Fang and Noe (2015) facilitates the analysis.

\section{The model}

I consider the following version of the model analyzed in Seel and Strack (2013). Each of two agents $i=1,2$ privately observes the realization of the stochastic process

$X_{t}^{i}=x_{0}+\sigma B_{t}^{i}$,

where $x_{0}>0$ denotes the starting value and the random terms $\sigma B_{t}^{i}$ are independent Brownian motions scaled by $\sigma \in \mathbb{R}_{+}$.

Each player chooses a stopping time $\tau^{i}$. The agents' stopping decision until time $t$ has to be $\mathcal{F}_{t}^{i}$-measurable, where $\mathcal{F}_{t}^{i}=\sigma\left(\left\{X_{s}^{i}\right.\right.$ : $s<t\}$ ) is the sigma algebra induced by the possible observations of the process $X_{s}^{i}$ before time $t$. Additionally, I restrict stopping times in two ways: First, they should have finite expectation, i.e., $\mathbb{E}\left(\tau^{i}\right)<\infty$. The second restriction is the loss constraint. Without loss of generality, assume that player 2 has a tighter constraint and that he has to stop once the process hits zero, i.e., $\tau^{i} \leq \inf \left\{t \in \mathbb{R}_{+}\right.$: $\left.X_{t}^{i}=0\right\}$ a.s.. Player 1 can make higher losses and thus he faces the weaker constraint $\tau^{i} \leq \inf \left\{t \in \mathbb{R}_{+}: X_{t}^{i}=\underline{x}\right\}$ a.s., where $\underline{x}<0$ is the difference in the loss constraints.

Note that a stopping strategy induces a distribution over the values of the process at the stopping time, which I denote by $F_{i}(x)=\mathbb{P}\left(X_{\tau^{i}}^{i} \leq x\right)$. The player who stops his process at the highest value wins a prize, which I normalize to one. Ties are broken randomly. Formally, the payoff/winning probability is

$\pi_{i}=\mathbf{1}_{\left\{X_{\tau^{i}}>X_{\tau^{j}}^{j}\right\}}+\frac{1}{2} \mathbf{1}_{\left\{X_{\tau^{i}}^{i}=X_{\tau^{j}}^{j}\right\}}$.

Each player maximizes the above winning probability.

Fang and Noe (2015) show that the stochastic contest model has the same Nash equilibrium distributions $F_{i}$ as a model in which players choose their cumulative distribution functions subject to the constraint that the expected value of the underlying random variable is $x_{0}^{i}$. Including the loss constraints, player 2 thus faces the choice of a cumulative distribution $F_{2}$ on $[0, \infty)$ subject to the capacity constraint (expected value equals $x_{0}$ ). Player 1 chooses a cumulative distribution $F_{1}$ on $[x, \infty)$ subject to the capacity constraint, where $-x>0$ is the amount of additional money which player 2 can lose.

\section{Equilibrium characterization}

In this section, I determine the Nash equilibrium of the contest. In equilibrium, player 1 must choose a cumulative distribution function $F_{1}$ which solves

$\max _{d F_{1} \geq 0} \int F_{2}(x) d F_{1}(x)$ s.t. $\int_{\underline{x}}^{\infty} x d F_{1}(x)=x_{0}$

and $F_{2}$ must solve

$\max _{d F_{2} \geq 0} \int F_{1}(x) d F_{2}(x) \quad$ s.t. $\int_{0}^{\infty} x d F_{2}(x)=x_{0}$.

The constraint captures the available capacity (the expected value should be $x_{0}$ ). The following proposition characterizes the Nash equilibrium of the game:

Proposition 1. In any Nash equilibrium, the cumulative distribution functions are

$F_{1}(x)= \begin{cases}0 & \text { if } x<\underline{x}, \\ \alpha & \text { if } x \in[\underline{x}, 0), \\ \alpha+(1-\alpha) \frac{x}{\bar{x}} & \text { if } x \in[0, \bar{x}], \\ 1 & \text { if } x>\bar{x},\end{cases}$ and

$F_{2}(x)= \begin{cases}0 & \text { if } x<0, \\ \beta+(1-\beta) \frac{x}{\bar{x}} & \text { if } x \in[0, \bar{x}], \\ 1 & \text { if } x>\bar{x},\end{cases}$

where

$\alpha=\frac{x_{0}-\sqrt{x_{0}^{2}-2 x_{0} \underline{x}}}{2 \underline{x}-x_{0}-\sqrt{x_{0}^{2}-2 x_{0}} \underline{x}}$,

$\beta=\frac{-\underline{x}}{x_{0}+\sqrt{x_{0}^{2}-2 x_{0} \underline{x}}-\underline{x}}$,

and

$\bar{x}=x_{0}+\sqrt{x_{0}^{2}-2 x_{0} \underline{x}}$.

Proof. The proof is split into four steps: verifying that both functions are cumulative distributions, the capacity constraints, the best-response properties and uniqueness.

Step 1 (Cumulative Distribution Function): To be a cumulative distribution, $F_{1}$ and $F_{2}$ have to be non-decreasing, right-continuous functions with $\lim _{x \rightarrow-\infty} F_{i}=0$ and $\lim _{x \rightarrow \infty} F_{i}=1$ for $i=1,2$. Clearly, these conditions are satisfied if $\alpha \in(0,1)$ and $\beta \in(0,1)$. To see that $\alpha \in(0,1)$, note that the numerator is negative since $x_{0}-\sqrt{x_{0}^{2}-2 x_{0} \underline{x}}<x_{0}-\sqrt{x_{0}^{2}}=0$. The denominator is also negative and has a larger absolute value than the numerator since $2 \underline{x}-x_{0}<x_{0}$. Thus, we obtain $\alpha \in(0,1)$. Since both the numerator and denominator in the expression of $\beta$ are positive with the denominator being larger than the numerator, we have $\beta \in(0,1)$.

Step 2 (Capacity Constraint): To verify the capacity constraint, I calculate the expected value and equate it to the constraint for both $F_{2}$ and $F_{1}$ in order to see for which values the equality holds.

$\int_{0}^{\bar{x}} x d F_{2}(x)=\frac{(1-\beta) \bar{x}}{2}=\frac{\left(1-\left(\frac{-\underline{x}}{\bar{x}-\underline{x}}\right)\right) \bar{x}}{2}=\frac{\bar{x}^{2}}{2(\bar{x}-\underline{x})}=x_{0}$.

Since $\bar{x}>x_{0}$, this yields $\bar{x}=x_{0}+\sqrt{x_{0}^{2}-2 x_{0} \underline{x}}$. Thus, $\beta=\frac{-\underline{x}}{\bar{x}-\underline{x}}=$ $\frac{-\underline{\underline{x}}}{x_{0}+\sqrt{x_{0}^{2}-2 x_{0} \underline{x}-\underline{x}}}$, i.e., the equality holds for the parameters given in the proposition.

For the first distribution, calculating the expected value setting it equal to $x_{0}$ yields

$$
\begin{aligned}
\int_{\underline{x}}^{\bar{x}} x d F_{1}(x) & =\alpha \underline{x}+\frac{(1-\alpha) \bar{x}}{2} \\
& =\alpha \underline{x}+\frac{(1-\alpha)\left(x_{0}+\sqrt{x_{0}^{2}-2 x_{0} \underline{x}}\right)}{2}=x_{0} .
\end{aligned}
$$

Thus, I obtain

$\alpha=\frac{x_{0}-\sqrt{x_{0}^{2}-2 x_{0} \underline{x}}}{2 \underline{x}-x_{0}-\sqrt{x_{0}^{2}-2 x_{0} \underline{x}}}$.

Hence, for the parameter values in the proposition, both capacity constraints are satisfied.

Step 3 (Existence): In the next step, I verify that two distributions are mutual best responses.

First of all, let me argue that the support of any best response to $F_{1}$ has to be a subset of $[0, \bar{x}]$ : towards a contradiction, for any 
distribution which places mass above $\bar{x}$, consider the following deviation. Player 2 shifts all mass above $\bar{x}$ to $\bar{x}$, which reduces the expected value, but keeps his winning probability unchanged, since $F_{1}(x)=1$ for all $x \geq \bar{x}$. He then shifts all mass in $[0, x)$ to the right such that the expected value increases back to the original value. Since $F_{1}(x)$ is strictly increasing on $[0, x)$, the winning probability of player 2 increases due to the shift, which violates the equilibrium assumption.

For any probability distribution $F_{2}$ with mean $x_{0}$ on $[0, \bar{x}]$, we get

$$
\begin{aligned}
\int_{0}^{\bar{x}} F_{1}(x) d F_{2}(x) & =\int_{0}^{\bar{x}} \alpha+(1-\alpha) \frac{x}{\bar{x}} d F_{2}(x) \\
& =\alpha+\frac{1-\alpha}{\bar{x}} \int_{0}^{\bar{x}} x d F_{2}(x)=\alpha+(1-\alpha) \frac{x_{0}}{\bar{x}} .
\end{aligned}
$$

Thus, the winning probability is constant, i.e., any distribution with mean $x_{0}$ on $[0, \bar{x}]$ is a best response to $F_{1}$. In particular, $F_{2}$ is a best response to $F_{1}$.

By the same argument as for player 2 , every best response to player 2's equilibrium distribution satisfies $F_{1}(\bar{x})=1$. Similarly, let me argue that $F_{1}(x)=F_{1}(x)$ for all $x \in(x, 0)$ : towards the contrary, assume that player 1 places mass in the interval $(\underline{x}, 0)$ with an expected value of $\tilde{x}$. Consider the deviation in which player 1 shifts all of the mass in $(x, 0)$ to $\bar{x}$ or $x$ which keeps the expected value constant, i.e., $a=\frac{\bar{x}-\tilde{x}}{\bar{x}-\underline{x}}$ is the fraction placed at $\underline{x}$ and $1-a$ is the fraction placed at $\bar{x}$. Since $F_{2}(x)=0$ for all $x \in[\underline{x}, 0)$ and $F_{2}(\bar{x})=1$, player 1 gains from the upward shift, but does not lose from the downward shift. Thus, there is a profitable deviation which contradicts the equilibrium assumption. The standard continuity argument for these models shows that against $F_{2}$ (which jumps at 0 ), player 1 does not place mass at zero. Summing up, the support of any best response distribution has to be a subset of $x \cup(0, \bar{x}]$.

Note that, as the mass point on $\underline{x}$ increases, player 2's expected value of the remaining probability mass also increases to satisfy the capacity constraint. More precisely, depending on $\alpha$, the conditional expectation is given by $E[x \mid x>0, \alpha]=\frac{x_{0}-\alpha \underline{x}}{1-\alpha}$.

Thus, we can write the payoff of player 1 as

$$
\begin{aligned}
\int_{0}^{\bar{x}} F_{2}(x) d F_{1}(x) & =(1-\alpha)\left(\beta+\frac{1-\beta}{\bar{x}} \mathbb{E}(x \mid x>0, \alpha)\right) \\
& =(1-\alpha)\left(\beta+\frac{1-\beta}{\bar{x}} \frac{x_{0}-\alpha \underline{x}}{1-\alpha}\right) .
\end{aligned}
$$

Rewriting, we obtain

$$
\begin{aligned}
\int_{0}^{\bar{x}} F_{2}(x) d F_{1}(x) & =\beta+\frac{(1-\beta) x_{0}}{\bar{x}}+\alpha\left(\beta\left(\frac{\underline{x}}{\bar{x}}-1\right)-\frac{x}{\bar{x}}\right) \\
& =\beta+\frac{(1-\beta) x_{0}}{\bar{x}},
\end{aligned}
$$

since

$\alpha\left(\beta\left(\frac{\underline{x}}{\overline{\bar{x}}}-1\right)-\frac{\underline{x}}{\overline{\bar{x}}}\right)=\alpha\left(\frac{-\underline{x}}{\overline{\bar{x}}-\underline{x}}\left(\frac{\underline{x}}{\overline{\bar{x}}}-1\right)-\frac{\underline{x}}{\overline{\bar{x}}}\right)=0$.

Hence, the winning probability is constant, i.e., any distribution with a support $\underline{x} \cup(0, \bar{x}]$ such that $\int_{x}^{\bar{x}} x d F_{1}(x)=x_{0}$ is a best response to $F_{2}$. In particular, the distribution $F_{1}$ is a best response.

Step 4 (Uniqueness): Since the game is a two-player constantsum game, $F_{1}$ has to be a best response to any equilibrium distribution of player 2 and $F_{2}$ has to be a best response to any equilibrium distribution of player 1 . By the arguments in Step 3, any equilibrium distribution has $\bar{x}$ as the right endpoint.

For any other candidate distribution $\tilde{F}_{1} \neq F_{1}$ with the same mean, we have $\tilde{F}_{1}(x)>F_{1}(x)$ for some $x>0$. Without loss of generality, assume that $F_{1}$ is continuous at $x$ (if $F_{1}$ places a mass point,

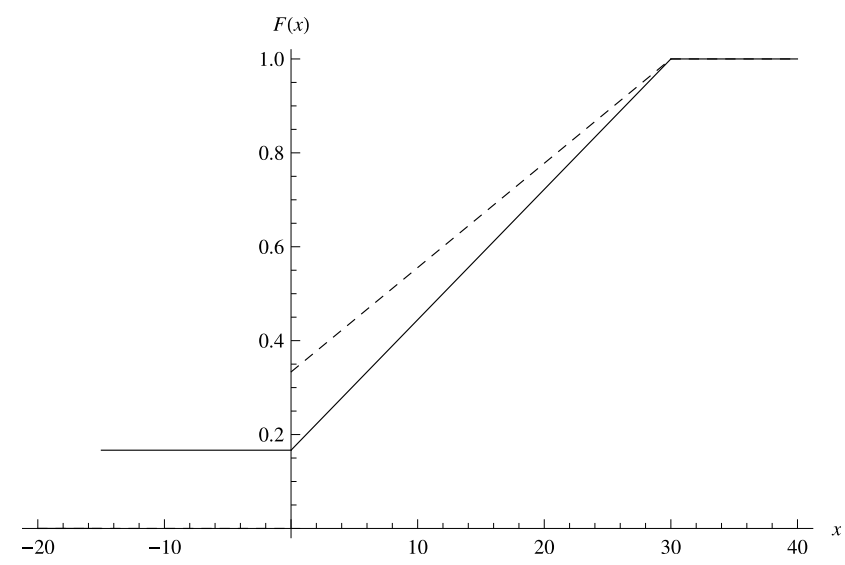

Fig. 1. Graph of the distributions for $x_{0}=10$ and $x=-15$. The distribution $F_{1}$ is shown in the solid line and the distribution $F_{2}$ in the dotted line.

there is an $\epsilon$-neighborhood in which the above inequality holds). I distinguish two cases:

If $x>x_{0}$, player 2 chooses the two-point distribution which only places mass at 0 and $x$. By the capacity constraint, the point mass at $x$ is $\frac{x-x_{0}}{x}$ and the point mass at 0 is $\frac{x_{0}}{x}$. Thus, $\pi_{2} \geq$ $\frac{x-x_{0}}{x} \tilde{F}_{1}(x)>\frac{x-x_{0}}{x} F_{1}(x)$, where the last term is the payoff in the equilibrium in the proposition (the minmax payoff of player 2 ). If $x<x_{0}$, the analogous argument holds with the points $x$ and $\bar{x}$. Hence, player 2 can obtain a higher payoff against $\tilde{F}_{1}$ than against $F_{1}$, which contradicts $\tilde{F}_{1}$ being an equilibrium distribution. A similar argument rules out equilibrium distributions for player 2 which differ from $F_{2}$.

For an illustration, consider an example in which $x_{0}=10$ and $x=-15$ (see Fig. 1). In this case, the equilibrium distributions simplify to

$F_{1}(x)= \begin{cases}0 & \text { if } x<-15, \\ \frac{1}{6} & \text { if } x \in[-15,0), \\ \frac{1}{6}+\frac{x}{36} & \text { if } x \in[0,30], \\ 1 & \text { if } x>30\end{cases}$

and

$F_{2}(x)= \begin{cases}0 & \text { if } x<0, \\ \frac{1}{3}+\frac{x}{45} & \text { if } x \in[0,30], \\ 1 & \text { if } x>30 .\end{cases}$

Intuitively, each player makes his rival indifferent between choosing any distribution on the support which satisfies the capacity constraint. The following payoff characterization relies on the previous indifference intuition and follows immediately from Step 3 in the proof of Proposition 1:

Corollary 1. The equilibrium payoff of player 1 is $\pi_{1}=\beta+(1-\beta) \frac{x_{0}}{\bar{x}}$ and the payoff of player 2 is $\pi_{2}=\alpha+(1-\alpha) \frac{x_{0}}{\bar{x}}$, where $\alpha, \beta$, and $\bar{x}$ are defined in Proposition 1.

\subsection{Comparative statics}

The next proposition analyzes the effect of loosening the loss constraint on the bankruptcy risk.

Proposition 2. In equilibrium, an increased maximal loss level of player 1 leads to a higher chance of bankruptcy for player 2. Increasing the maximal loss level of player 1 might increase or decrease his chance of bankruptcy, depending on the parameters. 
Proof. Recall that the chance of bankruptcy for player 2 is

$F_{2}(0)=\beta=\frac{-\underline{x}}{x_{0}+\sqrt{x_{0}^{2}-2 x_{0} \underline{x}}-\underline{x}}$.

The first derivative is

$\frac{\partial \beta}{\partial \underline{x}}=\frac{-x_{0}-\sqrt{x_{0}^{2}-2 x_{0} \underline{x}}-\underline{x} x_{0}\left(x_{0}^{2}-2 x_{0} \underline{x}\right)^{-\frac{1}{2}}}{\left(x_{0}+\sqrt{x_{0}^{2}-2 x_{0} \underline{x}}-\underline{x}\right)^{2}}$.

The denominator is positive and the numerator is negative, since

$-\sqrt{x_{0}^{2}-2 x_{0} \underline{x}}-\underline{x} x_{0}\left(x_{0}^{2}-2 x_{0} \underline{x}\right)^{-\frac{1}{2}}=\frac{-x_{0}^{2}+x_{0} \underline{x}}{\left(x_{0}^{2}-2 x_{0} \underline{x}\right)^{\frac{1}{2}}}<0$.

Thus, the bankruptcy risk decreases as the maximal loss decreases.

To prove the statement about player 1, observe that $\lim _{x \rightarrow 0} \alpha=$ 0 and $\lim _{x \rightarrow-\infty} \alpha=0$, while $\alpha>0$ for any negative value of $x$.

There are two mitigating effects which induce the nonmonotonicity of player 1's bankruptcy risk. As long as the difference in the constraints is small, an increase in the loss constraint of player 1 will lead to an increase in his bankruptcy risk, since he uses his additional leeway to gamble. However, for a large difference, already a low risk of bankruptcy allows the player to have a high expected value of his remaining probability mass. Therefore, at some point, the bankruptcy risk decreases as the player is allowed to make more losses. The rival, on the other hand, has to make up for the larger gap in the credit line by taking higher risks and thereby going bankrupt with an increasing probability.

\section{Discussion}

The problem with relative performance compensation in the presence of loss constraints and contest incentives is similar to incentives induced by a value-at-risk regulation (see Basak and Shapiro, 2001): it is rational for agents to use skewed gambles with a positive probability to lose the maximum. Below the threshold of player 2, it is a dominant strategy for the first player to gamble until he breaks even or he arrives at his maximal feasible loss level.

The intuition is similar to a manager who gambles for resurrection (see, e.g., Downs and Rocke, 1994) for the chance to prevent his firm from bankruptcy. In the present paper, it is rational for a fund manager to gamble until he either loses the maximum or has a chance to compete in the contest by breaking even.

Similar behavior, i.e., not stopping to gamble in the losses domain in order to break even are frequently observed in gambling data, even for experienced individuals such as regular poker players (Smith et al., 2009). One explanation in the literature is based on prospect theory combined with a lack of commitment; see, e.g., Kahneman and Tversky (1979), Thaler and Johnson (1990); Taleb (2004), or Barberis (2012). An evolutionary reason for such behavior in line with the present paper might be that people have learned incentives in contest situations and sometimes continue to use them in individual choice problems.

Finally, the construction bears some similarity to all-pay auctions with head starts (see, e.g., Konrad, 2002, Kirkegaard, 2012, Siegel, 2014, or Seel, 2014): one player places mass at the lowest value and both players are randomizing uniformly over a connected interval. Contrary to that setting, however, it is the advantaged player here who places mass at the lowest point and the size of the mass points differs.

\section{References}

Barberis, N., 2012. A model of casino gambling. Manage. Sci. 58, 35-51.

Basak, S., Shapiro, A., 2001. Value-at-risk based risk management: Optimal policies and asset prices. Rev. Financ. Stud. 14, 371-405.

Baye, M., Kovenock, D., de Vries, C., 1996. The all-pay auction with complete information. Econom. Theory 8, 291-305.

Downs, G.W., Rocke, D.M., 1994. Conflict, agency, and gambling for resurrection: The principal-agent problem goes to war. Amer. J. Polit. Sci. 38, 362-380.

Fang, D., Noe, T., 2015. Skewing the odds: Strategic risk taking in contests. Working Paper.

Feng, H., Hobson, D., 2015. Gambling in contests modelled with diffusions. Decis. Econ. Finance 38, 21-37.

Feng, H., Hobson, D., 2015. Gambling in contests with random initial law. Ann. Appl. Probab. in press-a.

Feng, H., Hobson, D., 2015. Gambling in contests with regret. Math. Finance http://dx.doi.org/10.1111/mafi.12069. in press-b.

Hillman, A., Samet, D., 1987. Dissipation of contestable rents by small numbers of contenders. Public Choice 54, 63-82.

Kahneman, D., Tversky, A., 1979. Prospect theory: An analysis of decision under risk. Econometrica 47, 263-292.

Kirkegaard, R., 2012. Favoritism in asymmetric contests: Head starts and handicaps. Games Econom. Behav. 76, 226-248.

Konrad, K.A., 2002. Investment in the absence of property rights; the role of incumbency advantages. Eur. Econ. Rev. 46, 1521-1537.

Seel, C., 2014. The value of information in asymmetric all-pay auctions. Games Econom. Behav. 86, 330-338.

Seel, C., Strack, P., 2013. Gambling in contests. J. Econom. Theory 148, 2033-2048.

Siegel, R., 2009. All-pay contests. Econometrica 77, 71-92.

Siegel, R., 2010. Asymmetric contests with conditional investments. Amer. Econ. Rev. 100, 2230-2260.

Siegel, R., 2014. Asymmetric contests with head starts and non-monotonic costs. Amer. Econ. J.: Microecon. 6, 59-105.

Smith, G., Levere, M., Kurtzman, R., 2009. Poker player behavior after big wins and big losses. Manage. Sci. 55, 1547-1555.

Taleb, N.N., 2004. Bleed or blowup? Why do we prefer asymmetric payoffs? J. Behav. Finance 5, 2-7.

Thaler, R.H., Johnson, E.J., 1990. Gambling with the house money and trying to break even: The effects of prior outcomes on risky choice. Manage. Sci. 36, 643-660. 